\title{
Aspartame-based Sweetener as a Strong Ant Poison: Falsifying an Urban Legend?
}

by

Jouni Sorvari* \& Marja-Katariina Haatanen

\begin{abstract}
Information about the usability of artificial sweeteners, mainly aspartame, for controlling pest ants has spread widely in the internet. With a laboratory experiment we tested the effect of an aspartame based sweetener on the mortality of the black garden ant Lasius niger, a common pest ant in kitchens in Europe. The aspartame-based sweetener was added to the laboratory jelly food of ants in the experimental group (16 colonies). The control group (14 colonies) received otherwise similar jelly but without the aspartame-based sweetener. During the 35 day period of experiment we did not find any signs of aspartame induced mortality in tested ants. In addition, 135 colony founding L. niger queens were submerged in a sweetener solution (artificial sweetener + distilled water) and 135 queens were submerged in distilled water (control). The overall mortality was very low $(<1.5 \%)$ and no between-group differences in mortality were found within 24 and 96 hours. Our results strongly oppose the rumors that aspartame sweeteners are effective as an ant poison, at least with a typical dose of household aspartame products.

Key words: ants, artificial sweetener, black garden ant, hoax, Lasius niger, pest control
\end{abstract}

\section{INTRODUCTION}

In ants, protein is used for egg formation and larval growth whereas carbohydrates are used as an energy source for adult workers (Brian 1983; Dussutour \& Simpson 2009), and thus it may have indirect, but important role in the production of offspring (Porter 1989). Accordingly, carbohydrates increased sexual investment in the ant Myrmica brevispinosa (Bono \& Herbers 2003).

Department of Biology, Section of Ecology, FI-20014 University of Turku, Finland

${ }^{*}$ Correspondence: J. Sorvari, Department of Biology, Section of Ecology, FI-20014 University of Turku, Finland; e-mail: jouni.sorvari@utu.fi, 
In the green-headed ants (Rhytidoponera sp.), carbohydrates increased the survival of larvae (Dussutour \& Simpson 2009).

Aspartame is an artificial sweetener used in sugar-free food and beverage products. Aspartame is widely and frequently used and it was discovered by chance over 40 years ago (Lajtha et al. 1994). It was at first used as a food additive over 20 years ago. Numerous studies have been made on various aspects of this compound, and the extensive literature includes observations for example on its absorption, metabolism, taste, structural analogies and effects on nutrition. Also several reviewers have raised concerns in regard to potential or anecdotal interactions. In the case of aspartame, concerns gives rise due to aspartame or its metabolic products (aspartic acid, phenylalanine, methanol) each of which may have effects on the nervous system in high concentrations in blood.

Information about the usability of artificial sweeteners, mainly aspartame, for controlling pest ants has spread widely in the internet. Also many gardening websites recommend aspartame as a method for ant control. Aspartame is paralleled as a neuropoison and is said to kill ants in a short period, e.g. within 24 hours. However, one internet site (Anonymous 2010) claims that the information about aspartame as an ant poison is a hoax, because aspartame was not poisonous in three different experiments. These three experiments, however, had methodological problems or in one case, the experiment was not conducted in a scientific manner.

In one of the experiments (Anonymous 2010), ants that were provided aspartame diet were said to thrive. However, the study contained only one nest fed with an aspartame-containing diet and two other nests were fed with another kind of diet, thus, clearly not reaching the number of replicates needed for a scientific experiment. In addition, the duration of the experiment was not reported. The author of this experiment remained anonymous.

The other experiments were made by exposing nest mounds of fire ants (Solenopsis invicta Buren, 1972) with dry aspartame sprinkled over nest mounds (Brown 2007), and with mild aspartame solution (1 table spoon of artificial sweetener containing aspartame and 3.785 liters of water) (Brown 2008). No differences were found between aspartame-treated mounds and untreated control plots in either year. In these experiments aspartame was applied to the nest mound and it is not sure that ants ate the aspartame at 
all. In fact, Tinti and Nofre (2001) reported that ants are not attracted by aspartame.

So the previous experiments can be doubted due to insufficient numbers of replicates or the fact that it is not known whether the ants consumed aspartame at all. Therefore, a careful reliable experiment is needed to assess the toxicity of aspartame based sweetener on ants. With a realistic dose (typical household artificial sweetener) we tested the effect of aspartame (together with asesulfame-K) containing food in laboratory tests on the mortality of the black garden ant Lasius niger (Linnaeus, 1758), a common pest ant in kitchens in Europe.

\section{MATERIALS AND METHODS}

Lasius niger is a common ant in Europe (Czechowski et al. 2002; Seifert 2007). Its colonies are monogynous i.e. there is only one queen at a time, and colonies contain up to ten thousand workers (Collingwood 1979; Czechowski et al.2002). In Finland it is often called the "sugar ant". As this name implies, L. niger is particularly attracted to sweet substances. In the presence of various species of aphids, it feeds aphid honey-dew (Fischer et al. 2001; Staedler \& Dixon 2008). Lasius niger is abundant in human environments as lawns, gardens and households, and it is often regarded as nuisance.

We reared 30 young small colonies of $L$. niger in laboratory in plastic boxes $(10 \times 8 \times 10 \mathrm{~cm})$. In the beginning of the experiment the nests contained a queen and approximately same number of workers and larvae (Table 1). The ants nested in test tubes. Humidity in test tubes was maintained by moist cotton. Walls of the nest boxes were lined with fluon (PTFE) to prevent escapes. The treatment group got a standard laboratory food jelly (Bhatkar \& Whitcomb 1970) enriched with artificial sweetener containing $2 \%$ of aspartame and $1 \%$ of asesulfame-K (Hermesetas ${ }^{\mathrm{mt}}$, Hermes Sweeteners Ltd, Zürich, Switzerland). The diet included one chicken egg, $62 \mathrm{ml}$ honey, $3.5 \mathrm{~g}$ artificial sweetener ( $7 \mathrm{mg}$ aspartame, $3.5 \mathrm{mg}$ asesulfame-K), $1 \mathrm{~g}$ vitamins, 1 $\mathrm{g}$ minerals and salts, $5 \mathrm{~g}$ agar and $500 \mathrm{ml}$ water. The control group $(\mathrm{N}=14)$ got otherwise the same food but without the artificial sweetener. Fresh food was offered daily ad libitum.

We kept the experiment running for 35 days (13 May-16 June 2011) in a climate chamber $\left(+25^{\circ} \mathrm{C}, 60 \% \mathrm{RH}, 12: 12\right.$ light:dark rhythm). The mortality 
of workers and queens was checked in a daily basis. Deceased workers were removed from nest boxes. The number of larvae was counted in the beginning and at the end of the experiment.

It is not known whether aspartame and asesulfame-K are absorbed into the haemolymph in digestion in ants. It is possible that aspartame is absorbed into the haemolymph via tracheal openings and causes toxic effects. Therefore we made a submerging experiment with 270 L. niger colony founding queens (21 July 2011). 135 queens were submerged briefly (approximately 1 second) in $10 \mathrm{ml}$ solution containing $9 \mathrm{~g}$ of distilled water and $0.13 \mathrm{~g}$ of artificial sweetener (2.6 $\mathrm{mg}$ aspartame, $1.3 \mathrm{mg}$ asesulfame-K). The control queens ( $\mathrm{N}$ $=135$ ) were dipped in a similar way in $10 \mathrm{ml}$ of distilled water. In order to avoid the possible contamination of the solution by formicid acid sprayed by the alarmed queens the solution was renewed after every 10 queens. The mortality was checked after 24 and 96 hours.

Statistical analyses were performed using SAS statistical software version 9.2 (SAS institute, 2001). The difference in the numbers of workers and larvae in the beginning and at the end of the experiment were analyzed with $t$ tests (the equality of variances were confirmed with Levene's tests; PROC TTEST). Differences in mortality and the development of larval number was analyzed with generalized linear models(PROC GENMOD) using binomial error term and logit link function. In the analyses of worker mortality the number of deceased workers was used as the dependent variable (events) with the number of all individuals (living and deceased) as the denominator (trials). The development of larval number was analysed in a similar way: the number of larvae at the end of the experiment was used as dependent event variable and the number of larvae in the beginning of the experiment as trial denominator. In the analysis of queen mortality the deceased queens were coded as 0 and live queens as 1 (binomial error term, logit link function).

\section{RESULTS}

\section{Colony rearing experiment}

Numbers of workers and larvae were similar between the treatment and control colonies both in the beginning and at the end of the experiment (Table 1). The average within colony mortality of adult workers was $10.9 \% \pm$ SD 14.2 in aspartame treatment colonies and $11.7 \% \pm$ SD 9.4 in the control colonies. 
Table 1. Mean numbers $( \pm S D)$ of adult workers and larvae in the aspartame based sweetener colonies $(\mathrm{N}=16)$ and in the control colonies $(\mathrm{N}=14)$. The variances were equal in all tests $(P=0.46-0.98)$. ABS = aspartame-based sweetener colonies.

\begin{tabular}{lllll}
\hline \hline & \multicolumn{2}{c}{ Workers \pm SD } & \multicolumn{2}{c}{ Larvae \pm SD } \\
& Beginning & End & Beginning & End \\
\hline ABS & $11.4 \pm 4.0$ & $12.4 \pm 5.3$ & $5.9 \pm 2.5$ & $1.3 \pm 1.9$ \\
Control & $10.1 \pm 3.3$ & $10.6 \pm 5.3$ & $5.9 \pm 2.5$ & $1.0 \pm 1.6$ \\
$t$ & 1.0 & 1.0 & 1.35 & 0.5 \\
$P$ & 0.32 & 0.34 & 0.19 & 0.63 \\
\hline \hline
\end{tabular}

The mortality did not differ statistically (Generalized Linear Model: $\mathrm{df}=1$, $\chi^{2}=0.12, P=0.72$ ). During the experiment one queen died in both groups. The mortality of queens was similar between treatments (Generalized Linear Model: $\mathrm{df}=1, \chi^{2}=0.01, P=0.92$ ).

We did not found dead larvae from any of the colonies at the end of the experiment. If larval mortality occurred the deceased larvae were consumed as protein food. However, it was possible to compare the development of larval number, i.e. the proportion of larvae at the end of the experiment from the larvae at the beginning of the experiment. No differences were found between the treatment and control colonies (Generalized Linear Model: $\mathrm{df}$ $\left.=1, \chi^{2}=0.01, P=0.90\right)$.

\section{Queen submerging experiment}

All of the queens survived the submerging treatment (checked immediately after the submerging). One queen was found dead in the control group and no dead queens were found in the artificial sweetener treatment group after 24 hours (Generalized Linear Model: $\mathrm{df}=1, \chi^{2}=1.39, P=0.24$ ). The mortality was one in the control group and three in the sweetener treatment group 96 hours after treatment (Generalized Linear Model: $\mathrm{df}=1, \chi^{2}=1.06$, $P=0.30)$.

\section{DISCUSSION}

Previous studies did not sufficiently monitor the consumption of aspartame by the ants. This is important in the light of Tinti and Nofre's (2001) choice 
experiment, where the ants (L. niger) were not interested in aspartame. We avoided this by giving the aspartame based sweetener as an un-separable part of the ants' jelly food, thus, the treatment ants were forced to eat it. The treatment group ants ate the aspartame containing food as readily as the control ants ate their non-aspartame containing, otherwise similar jelly food. In addition, we did not detect any signs of starvation (passivity, increased mortality of workers and larvae).

Many reports in the internet do not report in which form (e.g. liquid, hail, etc.) and how the aspartame exactly is given to the ants. If aspartame is spread on a nest as a sticky liquid (e.g. aspartame containing juice concentration), the ants may be killed not by the aspartame but by the stickiness of the product. In addition, observations that ant nests were "dead" soon after applying aspartame may be due to possible desertion of the nest after the nest material is contaminated by foreign substances.

Besides the amount, and how the aspartame is given to ants, aspartame may affect ants in time. According to the information spread on the web, aspartame killed ants in hours and days, not in weeks or months. In one web site (Anonymous 2010), where aspartame had no effect, the length of observation period is not reported and the number of replicates was way below scientific standards (only one aspartame treatment colony). Our study, with a sufficient number of colonies, lasted 35 days and no effects were discovered. In addition, in the submerging experiment the survival of high number of queens were monitored four days with no effects detected.

Our current results strongly oppose the rumor that aspartame based sweeteners are effective lethal poisons for ants. We used doses that are typical in household aspartame products and these doses were clearly sub-lethal. It is, of course, possible that higher doses can be toxic for ants. It must also be noted that we measured only the differences in mortality in a sterile laboratory environment. In theory it is possible that metabolic products of aspartame can disturb the immune system and cause increased mortality if the ants are exposed to pathogens at the same time. Therefore, a further study with variable doses and pathogen exposure needs to be conducted. 


\section{ACKNOWLEDGMENTS}

Salla-Riikka Vesterlund provided information on the use of aspartame as an ant poison. The study was funded by Emil Aaltonen's Foundation (JS) and by Finnish Cultural Foundation (MKH). Animal tests with insects do not violate any laws of Finland.

\section{REFERENCES}

Anonymous 2006 [cited 2011 December 1]. The world's best ant poison [Internet]. Available from: http://www.snopes.com/humor/iftrue/antpoison.asp

Bhatkar, A. \& W.H. Whitcomb 1970. Artificial diet for rearing various species of ants. Florida Entomologist 53:229-232.

Bono, J.M. \& J.M. Herbers 2003. Proximate and ultimate control of sex ratios in Myrmica brevispinosa colonies. Proceedings of the Royal Society of London B 270:811-817.

Brian, M.V. 1983. Social Insects: ecology and behavioural biology. London (UK): Chapman and Hall. 377 p.

Brown, E. 2007 [cited 2011 December 1]. Evaluation of aspartame as a mound treatment for red imported fire ant management. Integrated Pest Management - Urban IPM Program 2007. Texas AgriLife Extension Service, College Station, Texas, USA. pp. 65-67 [Internet]. Available from: http://fireant.tamu.edu/research/projects/pdf/ urbanipmhandbook2007edited.pdf

Brown, E. 2008 [cited 2011 December 1]. Evaluation of watered in aspartame as a mound treatment for red imported fire ant management. Integrated Pest Management - Urban IPM Program 2008. Texas AgriLife Extension Service, College Station, Texas, USA. pp. 33-35 [Internet]. Available from: http://fireant.tamu.edu/research/projects/pdf/ ipmmanual08a1.pdf

Collingwood, C.A. 1979. Fauna Entomologica Scandinavica. Volume 8, The Formicidae (Hymenoptera) of Fennoscandia and Denmark.Klampenborg(Denmark): Scandinavian Science Press. 174 p.

Czechowski, W.,A.Radchenko \& W.Czechowska 2002. The ants (Hymenoptera, Formicidae) of Poland. Warsaw (Poland): Museum and Institute of Zoology PAS. 200 p.

Dussutour, A. \& S.J. Simpson 2008. Description of a simple synthetic diet for studying nutritional responses in ants. Insectes Sociaux 55:329-333.

Fischer, M.K., K.H. Hoffmann \& W. Völkl 2001. Competition for mutualists in an anthomopteran interaction mediated by hierarchies of ant-attendance. Oikos 92:531541.

Lajtha, A., M.A. Reilly \& D.S. Dunlop 1994. Aspartame consumption: lack of effects on neural function. Journal of Nutritional Biochemistry 5:266-283.

Porter, S.D. 1989. Effects of diet on the grow th of laboratory fire ant colonies (Hymenoptera: Formicidae). Journal of the Kansas Entomological Society 62:288-291. 
Seifert, B. 2007. Die Ameisen Mittel- und Nordeuropas. Tauer (Germany): lutra Verlagsund Vertriebsgesellschaft. 368 p.

Staedler, B. \& A.F.G. Dixon 2008. Mutualism: Ants and their insect partners. Cambridge (UK): Cambridge University Press. 226 p.

Tinti, J.-M. \& C. Nofre 2001. Responses of the ant Lasius niger to various compounds perceived as sweet in humans: a structure-activity relationship study. Chemical Senses 26:231-237. 